\title{
Collaborative Health Informatics: A Multidisciplinary Approach
}

\author{
Ovidiu Noran \\ Griffith University Australia, School of ICT, O.Noran@griffith.edu.au
}

\begin{abstract}
Modern healthcare is confronted with serious issues that are threatening its sustainability. Increasing costs and complexity, progressive population ageing and rapidly spreading pandemics triggered by new disease strains and by increased population displacements fuelled by conflicts and climate change are all major contributors to the healthcare quandary. In this context, effective cooperation and interoperability of the participants in the healthcare effort becomes paramount. Collaboration is an essential factor but also a major challenge, as typically healthcare institutions are hierarchical and heterogeneous due to various administrative, geographical and historical reasons. As the pressure on healthcare resources and management cost is constantly increasing, governments can no longer rely on information and organisational silo paradigms for managing population wellbeing. Innovative holistic and integrated models and procedures taking into account all essential aspects, elements, participants and their life cycle are necessary if these challenges are to be successfully met. Based on previous research and applications, this paper argues that such necessary artefacts can be built using a life cycle-based holistic paradigm enabled by advances in Information Systems, Interoperability, Collaborative Networks and Enterprise Architecture. This approach aims to provide a sound platform for sustainable solutions to both long and short-term challenges to population health and well-being.
\end{abstract}

\section{Introduction}

The healthcare environment is under escalating pressure from population ageing, risk of drug-resistant pandemics, increasing complexity and rising costs. In this context, legacy silo-type governance models have lost much of their relevance as collaboration is nowadays a mandatory requirement for survival and progress.

Unfortunately, due to complex regional, historical, organisational and political reasons, there are significant challenges in managing the internal and external collaboration and interoperation of the typically heterogeneous set of participants involved in the healthcare endeavour. This constitutes a particularly critical issue in handling acute health incidents (e.g. pandemics) that require prompt response and claim resources and capabilities beyond those of any particular individual 


\section{Ovidiu Noran}

healthcare organisation. New innovative and integrated models, methods and tools are required in order to enable proper inter-professional and inter-organisational cooperation, so as to meet these serious long and short term healthcare challenges.

Previous research [1,2] has investigated the use of Collaborative Networks (CN) [3] and Enterprise Architecture (EA) [4] concepts and methodologies in supporting generic disaster management efforts. This paper aims to build on the previous results by extending this multidisciplinary approach and focusing it on the healthcare-specific Information Systems (IS) area - hereafter, considered synonymous to Health Informatics [5] (HI). It is hypothesised that this approach will allow addressing the above-mentioned issues in a multifaceted life cycle-based, holistic and integrated manner. Owing to this new approach, the resulting models are expected to enable a prompt and efficient response by agile and synergic teams to both acute and long-term challenges to population health and well-being.

\section{Challenges in Healthcare Management Collaboration}

Healthcare has made significant advances in the last century, such as the development and wide use of vaccines, eradication of serious diseases and large reductions in communicable disease epidemics and chronic diseases [5, 6].

While solving some very important problems, some of these advances have unfortunately also contributed to a new set of challenges faced by the public and private healthcare infrastructure and organisations. For example, population growth and ageing triggered by increased longevity [6], while reflecting mankind progress and providing benefits [7], also brings significant social security and healthcare challenges [8]. Another major concern are the increasingly complex health incidents such as pandemics, owing to new strains of diseases [9], population displacements fuelled by regional conflicts and climate change [10].

Whereas healthcare as a system has become somewhat more organised, it has also become more expensive, complex and difficult to manage. New technologies are making considerable progress towards supporting collaborative healthcare; however, the intricate nature of the host organisations involved presents significant impediments to their successful transfer and diffusion [11] that includes interactional user resistance to the new systems [12].

Research in the field also confirms that the main barriers to healthcare cooperation are of organisational and cultural nature [13-16]. Thus, collaboration between participants in the healthcare effort does not automatically occur. It must be "constructed, learned, and once established, protected" [13]. Like most human-related processes, collaboration can neither be successfully forced on the participants nor achieved in a short time.

The divergent perceptions and expectations of the parties involved [15], owing to a traditionally strong hierarchy and marked difference in status between partners [16], can be best dealt with by the higher ranking participants. They can pro- 
mote collaboration and trust by employing a participatory and inclusive approach [17] which will also build a beneficial sense of security [18].

Inter-professional and inter-organisational collaborative healthcare is encouraged in various medical and emergency response reports, conferences and journals (e.g. [19-24]) as well as in international projects. For example, the BRAID [25] project deliverables advocate the necessity for collaborative healthcare ecosystems [26] supported by integrated assistive services and infrastructure, as part of a 'healthy living and ageing' paradigm [24]. Unfortunately however, the extent of actual cooperation in healthcare is still limited.

In disaster management, often there is a tendency of the higher ranking and more powerful organisation(s) to override or exclude some participants, adopting a 'central command' approach in preference to a cooperative one [27]. This is not desirable as successful disaster management relies on a wide range of community, economic, social-psychological, and political resources. This cooperation brings communities together, gives them a sense of usefulness (ibid.) and thus also alleviates the negative psychological effects such as uncertainty, anguish, confusion, panic etc that are significantly augmented in pandemic-type situations.

\section{A Combined Approach for Collaborative Healthcare}

Efficient healthcare collaboration requires that organisational cultures, processes and resources of the participants acquire suitable preparedness [19, 28, 29], with ethics playing a prominent role [30,31]. This endeavour requires access to a plethora of interdisciplinary information and knowledge not always easily accessible to planners and disaster managers. Therefore, multidisciplinary and participatory analysis and design [32] represent important collaborative healthcare enablers that helps integrate all necessary scientific, administrative, social and political aspects into a whole-system approach [20, 28, 33].

The following sub-sections briefly explain the potential contributions of the IS, Interoperability, $\mathrm{CN}$ and EA disciplines to the proposed combined approach.

\subsection{Healthcare Informatics as a Healthcare Information System}

Due to their close relationship, the area of Information Systems (IS) research provides a sound platform for the study of the more specific HI collaboration; therefore, throughout this research we have drawn on the rich and diverse field of IS research. Major IS issues such as politics, organisational culture, user resistance, difficulties of research results and information technology diffusion in the organisations, privacy, quality of information, ethics, etc all apply to collaborative HI to various degrees as shown throughout this paper (and somewhat more detailed in Section 2). 


\subsection{Interoperability as a Measure of Cooperation}

The concept of interoperability is often used as a measure of IS cooperation capability (see e.g. the Levels of Information System Interoperability taxonomy in the Department of Defence Architecture Framework v1 [34]) and it is therefore also useful in the analysis of HI collaboration.

The analysis of interoperability in the HI domain must include some important aspects, such as extent, approach and aspects covered. As shown in previous research [2], too high an interoperability degree (close to total integration) would be detrimental as it would mean a significant loss of autonomy, which is not desirable (e.g. in crisis situations). On the other extreme, minimal IS interoperability (compatibility) of the healthcare or healthcrisis management effort participants would be only good as a starting point (which is often not met unfortunately). Thus, 'optimal interoperability' lies somewhere between total integration and minimal, depending on the specific healthcare or health crisis management endeavour [ibid.].

In relation to the interoperability approach, the full integration and federalisation options specified in ISO14258 [35] did not seem to achieve the desired results due to organisational heterogeneity and the impossibility to properly negotiate in the limited time available in the case of a disaster event. The apparently more suitable unified approach [ibid.] assumes that ontology is negotiated in advance. For this to happen however, the organisations need to 'spend time together' in order to agree on the meanings associated with the concepts used to exchange knowledge.

Interoperability aspects are provided by various standards [ibid.] and frameworks (e.g. European Interoperability Framework (EIF)[36], IDEAS project [37], ATHENA Interoperability Framework (AIF)[38], Chen's Interoperability Framework [39]). As all these frameworks have overlapping and complementary areas, a combined model has been constructed and applied in [2] for identifying the relevant aspects for generic disaster management. The results largely apply to HI interoperability as well; thus, the data and process areas are the most urgent in a disaster situation as the ability to extract and exchange data from heterogeneous sources providing high volume and often unreliable data is paramount to being aware of the conditions on the ground and avoiding unknown and potentially lifethreatening situations for emergency crews. Prior agreements on data format and especially on meaning are essential. Note that 'process interoperability' here concerns the capability to perform joint operations but also to 'take over' and perform a process instead of a disaster management task force participant that may have been temporarily or permanently disabled.

The pragmatic interoperability aspect [40] relates to the capacity but also willingness of the participants to interoperate, suggesting that the human component of the HI needs attention prior to task force formation as to allow gaining trust and knowledge between the organisations.

Organisational interoperability is an important aspect in disaster management, as task force participants may often exhibit significant organisational structure diversity that is reflected in their IS. Issues identified by Chen [39] based on the EIF 
[36], such as responsibility and authority, seem to imply that the roles and hierarchy within a disaster management task force must be clearly understood and reflected in their IS so that the focus is kept on managing the disaster event.

Cultural interoperability [40] appears to be one of the hardest problems. Similar to obtaining pragmatic and semantic interoperability, the only current solution appears to be the regular immersion of the participant organisations in each other's cultures, which facilitates the transfer and conversion of tacit and explicit knowledge between the participants. This recurring 'co-habitation' concept could be facilitated by the Collaborative Network concept explained in the next section.

\subsection{Collaborative Networks for Healthcare}

The concept of networks in disaster management and recovery as an alternative to a centralised command and control approach has been advocated, studied and applied to some extent for a number of years with mixed results (e.g. [27, 41-43]). While providing valuable data, such attempts appear to have two main shortcomings. Firstly, they appear to use untested models focusing on a specific aspect at a time, rather than employing a proven set of integrated models in a whole-system approach. Secondly, the life cycle aspect of the participant organisations, networks and other relevant entities (including the disaster event/s) appears to be less addressed. As all participants and their systems are evolving, it is essential that the interactions required for collaboration and interoperation be considered in an integrated life cycle context.

In attempting to tackle these issues, it has been observed that the healthcare challenges identified in the critical literature review describe a situation similar to that of commercial enterprises who, owing to a global business environment, find themselves compelled to tackle projects requiring resources beyond their own staff, knowledge and time capabilities. Their usual reaction to this problem is to set up or join so-called Collaborative Networks (CNs) that act as breeding environments for Virtual Organisations (VOs) who are promptly created in order to bid for and (if successful) complete projects requiring combined resources and know-how. The view of CNs as social systems composed of commitments, who absorb uncertainty and reduce complexity [44] also supports their use in healthcare and health disaster management projects that typically display such features.

The CNs and VOs set up for the healthcare domain would have specific features. For example, the competitive motivations of commercial CN participants that guide their decisions to create / join / remain / leave the network would transform into the need to cope with increasingly complex health challenges and healthcare systems. The use of reference models, customary in commercial CNs, could be limited by the diversity in scale and type of healthcare incidents [45]. The Health Management CN (HMCN) would create health management VOs 
(HMVO) for long term projects (e.g. as described in [46]), or task forces (HMTF) for shorter term and more intense events (e.g. pandemics).

Importantly, for a HMCN to function, the lead partner/s (here, government emergency management / healthcare agencies) need to take a participatory and inclusive approach. Thus, scientific, faith and community representatives and all relevant non-governmental and volunteer organisations must also be included in the setup and operation of the HMCN, in addition to the typical participants such as hospitals, allied healthcare [47], fire and rescue services, etc.

\begin{tabular}{|c|c|c|c|c|c|}
\hline $\begin{array}{l}\text { Healthcare and Health } \\
\text { Informatics Issue }\end{array}$ & $\begin{array}{l}\text { Applic } \\
\text { ability }\end{array}$ & $\begin{array}{c}\text { Input from } \\
\text { Collaborative Networks }\end{array}$ & $\begin{array}{l}\text { Input from } \\
\text { Information } \\
\text { Systems }\end{array}$ & $\begin{array}{l}\text { Input from } \\
\text { Enterprise } \\
\text { Architecture }\end{array}$ & $\begin{array}{c}\text { Input from } \\
\text { Interoperability }\end{array}$ \\
\hline $\begin{array}{l}\text { Divergent perceptions of } \\
\text { the participants' roles }\end{array}$ & $\begin{array}{l}\text { Long \& } \\
\text { Short } \\
\text { Term }\end{array}$ & $\begin{array}{l}\text { Clear, agreed roles for } \\
\text { network and task force } \\
\text { participants }\end{array}$ & $\begin{array}{l}\text { Identify / address the } \\
\text { root problems in } \\
\text { divergent perceptions }\end{array}$ & \begin{tabular}{|l|} 
Integrated modelling \\
of all necessary \\
aspects of \\
collaboration
\end{tabular} & \\
\hline $\begin{array}{l}\text { Lack of trust between } \\
\text { partiticipants }\end{array}$ & $\begin{array}{l}\text { Long \& } \\
\text { Short } \\
\text { Term }\end{array}$ & $\begin{array}{l}\text { Trust building in time, } \\
\text { within the network }\end{array}$ & & $\begin{array}{l}\text { Promote trust by } \\
\text { common } \\
\text { understanding of } \\
\text { models }\end{array}$ & $\begin{array}{l}\text { Methods to tackle } \\
\text { cultural and } \\
\text { organisational } \\
\text { interoperability }\end{array}$ \\
\hline $\begin{array}{l}\text { Poor life cycle } \\
\text { management of task } \\
\text { forces / collaborative } \\
\text { healthcare IS }\end{array}$ & $\begin{array}{l}\text { Long \& } \\
\text { Short } \\
\text { Term }\end{array}$ & & $\begin{array}{l}\text { Identified / addressed } \\
\text { problems in } \\
\text { healthcare } \\
\text { management }\end{array}$ & \begin{tabular}{|l|} 
Intrinsic life cycle \\
context to the \\
creation and \\
operation of network \\
and task forces
\end{tabular} & $\begin{array}{l}\text { Interoperability reqs. } \\
\text { and capabilities in } \\
\text { respect to current life } \\
\text { cycle phase/s }\end{array}$ \\
\hline $\begin{array}{l}\text { Difficulties setting up and } \\
\text { operating Collaborative } \\
\text { Healthcare (e.g. unclear } \\
\text { rules, disagreement on the } \\
\text { present and future } \\
\text { situations) }\end{array}$ & \begin{tabular}{|l|} 
Long I \\
Short \\
Term
\end{tabular} & \begin{tabular}{|l|} 
Participatory design, \\
inclusive approach by lead \\
network partner. Agreed \\
upon models of Networks \\
as Collaborative \\
Healthcare Ecosystems.
\end{tabular} & $\begin{array}{l}\text { Participatory design } \\
\text { methods and models }\end{array}$ & $\begin{array}{l}\text { Integrated modelling } \\
\text { of the creation and } \\
\text { operation of } \\
\text { complex projects }\end{array}$ & \\
\hline $\begin{array}{l}\text { Focus on a limited set of } \\
\text { interoperability aspects }\end{array}$ & $\begin{array}{l}\text { Long / } \\
\text { Short } \\
\text { Term }\end{array}$ & & $\begin{array}{l}\text { Cooperative IS } \\
\text { requirements }\end{array}$ & $\begin{array}{l}\text { A whole-system } \\
\text { approach integrating } \\
\text { all relevant aspects }\end{array}$ & $\begin{array}{l}\text { Identify all relevant } \\
\text { aspects based on } \\
\text { interop. frameworks }\end{array}$ \\
\hline $\begin{array}{l}\text { Information sharing and } \\
\text { cooperation impeded by } \\
\text { traditional hierarchy }\end{array}$ & \begin{tabular}{|l|} 
Long I \\
Short \\
Term
\end{tabular} & $\begin{array}{l}\text { Information and process } \\
\text { interoperability achieved } \\
\text { at network level and } \\
\text { carried on in task forces } \\
\text { created }\end{array}$ & $\begin{array}{l}\text { Methods to improve } \\
\text { Hl cooperation in } \\
\text { hierarchical } \\
\text { organisations }\end{array}$ & & $\begin{array}{l}\text { Methods to tackle } \\
\text { cultural and } \\
\text { organisational } \\
\text { interoperability }\end{array}$ \\
\hline $\begin{array}{l}\text { Tendency to overrule } \\
\text { rather than cooperate in } \\
\text { task forces }\end{array}$ & $\begin{array}{l}\text { Short } \\
\text { Term }\end{array}$ & \begin{tabular}{|l|} 
Cooperation previously \\
agreed upon and built in \\
the task forces created by \\
the network
\end{tabular} & & & \\
\hline $\begin{array}{l}\text { Lack of preparedness to } \\
\text { participate in a task force } \\
\text { on short notice }\end{array}$ & $\begin{array}{l}\text { Short } \\
\text { Term }\end{array}$ & $\mid \begin{array}{l}\text { Participant preparedness } \\
\text { built in advance within the } \\
\text { network, ready for prompt } \\
\text { taskforce / VO creation }\end{array}$ & & & $\begin{array}{l}\text { Identify and address } \\
\text { all required } \\
\text { Interoperability } \\
\text { aspects of network } \\
\text { partners }\end{array}$ \\
\hline $\begin{array}{l}\text { Difficult discovery and } \\
\text { assessment of suitable } \\
\text { participants for an effective } \\
\text { and agile task force }\end{array}$ & $\begin{array}{l}\text { Short } \\
\text { Term }\end{array}$ & \begin{tabular}{|l|} 
Task forces created \\
promptly using pre- \\
qualified network partners \\
implementing agreed upon \\
processes.
\end{tabular} & & $\begin{array}{l}\text { Previous research } \\
\text { results in 'methods } \\
\text { to build methods' for } \\
\text { creation and } \\
\text { operation of } \\
\text { complex projects }\end{array}$ & $\begin{array}{l}\text { Interoperability and } \\
\text { agility of task force } \\
\text { inherited from the } \\
\text { network }\end{array}$ \\
\hline
\end{tabular}

Fig.1 Sample barriers in establishing collaborative HI and some potential solutions offered by combining the CN, IS, EA and Interoperability disciplines selected in the proposed approach 
Adopting a CN approach for health disaster management provides benefits going beyond mere technical and syntactic-type interoperability. Thus, the participants in a HMCN have the time and suitable environment to overcome the previously described hierarchical, organisational and cultural interoperability [40] barriers and achieve the required preparedness. This is essential in the prompt and successful setup of HMTFs for disasters and in the creation and operation of continuing HMVOs for long term healthcare challenges such as population ageing.

\subsection{The Enterprise Architecture Perspective}

IS and HI collaboration requirements are inherently linked to the current life cycle phase(s) of the host organisations; it is therefore essential that the analysis of possible cooperation improvements is performed in a life cycle context. It is hereby argued that an optimal way to integrate the life cycle aspect in a collaborative HI scenario is by using EA approach.

EA is seen in this context as a holistic change management paradigm that bridges management and engineering best-practice, providing the "[...] key requirements, principles and models that describe the enterprise's future state. [...] EA comprises people, processes, information and technology of the enterprise, and their relationships to one another and to the external environment" [4]. This EA definition reinforces the view of CNs as social systems composed of commitments [44] and IS / HI as socio-technical systems [48] with voluntaristic people [49] in a complex organisational, political and behavioural context [12, 50, 51]. As such, EA is capable of providing a framework integrating all necessary aspects in a life cycle-based set of models ensuring the consistency and sustainability of complex projects. The fundamental role played by EA in this approach and use of EA artefacts is exemplified within in a typical DMCN scenario in the next section.

\section{Life Cycle Integration Modelling for Collaborative Healthcare}

Integration modelling of collaborative $\mathrm{HI}$ will only be successful if accomplished collaboratively, with all the network participants [33]. The proposed approach supports this audience variety by graphical models and complexity management. While several EA frameworks would have been suitable for this example, we have selected the modelling framework (MF) provided by GERAM (Generalised Enterprise Reference Architecture and Methodology), described in ISO 15704:2005 [35]. This MF provides a large set of aspects, importantly including life cycle, management, organisation and human. For example, Fig.2 right shows the sample use of the GERA MF life cycle viewpoint to define and map the life cycle phases of a health incident on typical health disaster management activities [52]. 
Fig.3 left shows a modelling construct based on a subset of the GERA MF containing orthogonal life cycle, management and information viewpoints. Further on, a projection of this construct is used in Fig.3 to depict an information-based dynamic business model of HMCN and HMTF / HMVO creation and operation.

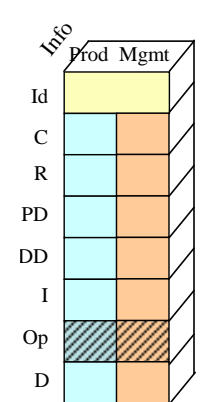

\begin{tabular}{|l|l|l|}
\hline $\begin{array}{c}\text { Health Incident Life Cycle } \\
\text { Phase (GERA MF) }\end{array}$ & $\begin{array}{c}\text { Health Disaster } \\
\text { Management Phase }\end{array}$ & Comment \\
\hline \hline Identification & Prevention & Identification of the Health Hazard \\
\hline Concept & Prevention & Response Required? Why / why not? \\
\hline Requirements & Preparation & Response Requirements \\
\hline Preliminary Design & Preparation & Response Solution (Principles, Policies) \\
\hline Detailed Design & Preparation & $\begin{array}{l}\text { Detailed Response Solution; Prepare Partners for fast } \\
\text { Task Force Implementation }\end{array}$ \\
\hline Implementation & Response & Create Health Disaster Management Task Force \\
\hline Operation & Response & Deploy, Respond \\
\hline Decommisssioning & Recovery & $\begin{array}{l}\text { Decommissison the Disaster Management Task Force } \\
\text { or reconfigure it for Recovery }\end{array}$ \\
\hline
\end{tabular}

Fig.2 Mapping a health incident on disaster management using GERA MF life cycle phases

The arrows in Fig.3 show influences and contributions among the entities involved in the long and short term healthcare endeavour. Thus, healthcare organisations HO (e.g. hospitals), allied health professionals (AHP) and scientific, faith and other communities representatives (CSFR) all contribute to the design and operation of a HMCN in its various life cycle phases. These contributions may also extend directly to the design and operation of the HMTFs/HMVOs created by the HMCN, and to the health management projects (HMPs) created by the HTMF/ HMVOs. Influences and contributions also come from 'non-physical' artefacts such as emergency management laws (EML), pandemic preparedness (PPF), or ehealth strategies / frameworks (EHF) [53]. Access to properly aggregated, understandable information [54] is provided by HTMFs / HMVOs. Population, organisations and community representatives' feedback flows to Government agencies (GDMAs) and the HMTFs/ HMVOs and may result in changes at various levels.

The arrow from HMTF/HMVO's Management side of the Operation life cycle phase to some of its upper phases represents a very important (if limited) 'self redesign' capability, showing a need for the HMTF to be agile and adapt in real time in the face of rapidly changing conditions on the ground that are typical of some disaster events. However, any major HMTF/HMVO reconfiguration (e.g. involving Requirements or Architectural Design life cycles) must involve the HMCN participants and the influence of the other entities on HMCN, as shown in Fig.3.

Note that a high-level model such as shown in Fig.3 does not aim to provide all the details necessary for actual $\mathrm{HI}$ implementation. Rather, its main purpose is to facilitate stakeholder common understanding and consensus on the present state and support the selection of the optimal future state. Such models can provide checklists of the 'things' that need to be considered in the collaborative healthcare endeavour and spell out the interactions between them in the context of their life cycles. They can be used to build scenarios representing various degrees of autonomy and agility of the participants and their systems. Once consensus on present 
and future has been achieved these models can be evolved into design and implementation blueprints. Note that a complete analysis (not possible here due to space limitations) should include an integrated set of models depicting all required aspects, such as process, resource, organisation, decision, etc.

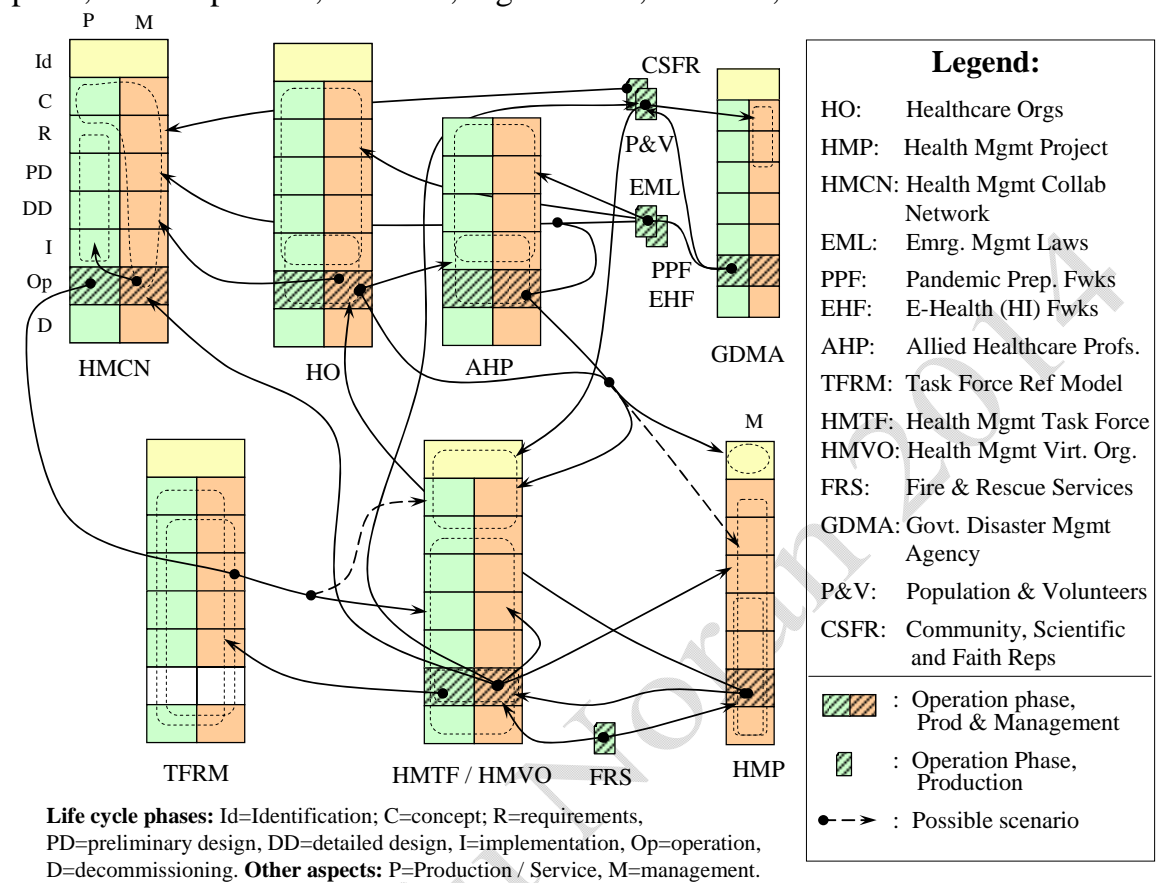

Fig.3 Sample HI dynamic business model integrating life cycle, management and information viewpoints in a possible health management collaborative network and task force scenario

\section{Conclusions and Further Work}

Healthcare and HI need to adopt a collaborative approach in order to cope with major contemporary challenges. Politics, hierarchy, diverging perceptions, lack of trust, dissimilar organisational cultures and limited life cycle-based perspective of the healthcare participants' roles and interactions are collaboration barriers. This paper has argued and attempted to demonstrate that an optimal way to address these issues is to adopt a combined interdisciplinary approach that allows drawing upon a rich repository of Information Systems, Collaborative Networks, Enterprise Architecture and Interoperability research state-of-the-art results.

The paper makes a theoretical contribution by using four disciplines to advance collaborative healthcare research and a practical contribution by providing an ex- 
ample of how $\mathrm{CN}$ concepts can be employed from an EA perspective in order to model a collaborative healthcare solution to health and well-being challenges.

This is just the beginning; the proposed approach will be further developed and tested in a variety of healthcare management and health disaster case studies in order to verify, validate and refine it.

\section{References}

1. Noran, O., Towards A Collaborative Network Paradigm for Emergency Services. Adaptation and Value Creating Collaborative Networks - IFIP Advances in Information and Communication Technology, 2011. 362: p. 477-485.

2. Noran, O. and P. Bernus, Effective Disaster Management: An Interoperability Perspective. Lecture Notes in Computer Science, 2011. 7046: p. 112-121.

3. Camarinha-Matos, L. and H. Afsarmanesh, Collaborative Networks: A new scientific discipline. Journal of Intelligent Manufacturing, 2005. 16: p. 439-452.

4. Gartner Research. IT Glossary. 2012 [cited 2012; Available from: http://www.gartner.com/technology/it-glossary/enterprise-architecture.jsp.

5. Fielding, J.E., Public Health in the Twentieth Century: Advances and Challenges. Annual Reviews in Public Health, 1999. 20: p. xiii-xxx.

6. World Health Organization. The world health report 1998---life in the 21st century: a vision for all. 1998 [cited 2013 April]; Available from: http://www.who.int/whr/1998/en/whr98_en.pdf.

7. Healy, J. The Benefits of an Ageing Population - Discussion Paper 63. The Australia Institute 2004 [cited 2013 April]; Available from: http://www.tai.org.au/documents/dp fulltext/DP63.pdf.

8. International Labour Organisation. Ageing societies: The benefits, and the costs, of living longer. 2009 [cited 2013 March]; Available from: http://www.ilo.org/global/publications/magazines-andjournals/world-of-work-magazine/articles/WCM 041965/lang--en/index.htm.

9. Kilbourne, E.D., Influenza Pandemics of the 20th Century. Emerg. Infect. Dis., 2006. 12(1).

10. Donohoe, M., Causes and health consequences of environmental degradation and social injustice. Social Science and Medicine, 2003. 56(3): p. 573-587.

11. Southon, F.C., C. Sauer, and C.N. Grant, Information technology in complex health services: organizational impediments to successful technology transfer and diffusion. J Am Med Inform Assoc. 1997 Mar-Apr;4(2):112-24., 1997. 4(2): p. 112-124.

12. Markus, M.L., Power, politics, and MIS implementation. Comm ACM, 1983. 26: p. 430-444.

13. Wilson, K., et al., Nurse Practitioners' Experience of Working Collaboratively with General Practitioners and Allied Health Professionals in NSW, Australia. Australian Journal of Advanced Nursing, 2005. 23(2): p. 22-27.

14. Braude, R.M., People and Organizational Issues in Health Informatics. J Am Med Inform Assoc., 1997. 4(2): p. 150-151.

15. Krogstad, U., D. Hofoss, and P. Hjortdal, Doctor and nurse perception of interprofessional cooperation in hospitals. International Journal for Quality Health Care, 2004. 16(6): p. 491-497.

16. Ramanujam, R. and D.M. Rousseau, The Challenges Are Organizational, Not Just Clinical. Journal of Organizational Behavior, 2006. 27(7): p. 811-827. 
17. Baker, D., R. Day, and E. Salas, Teamwork as an essential component of high reliability organizations. Health Services Research, 2006. 41(4): p. 1577-1598.

18. Nembhard, I.M. and A.C. Edmondson, Making It Safe: The Effects of Leader Inclusiveness and Professional Status on Psychological Safety and Improvement Efforts in Health Care Teams. Journal of Organizational Behavior, 2006. 27(7): p. 941-966.

19. Kapucu, N., T. Arslan, and F. Demiroz, Collaborative emergency management and national emergency management network. Disaster Prevention and Management, 2010. 19(4): p. 452-468.

20. Utah Department of Health. Governor's Task Force for Pandemic Influenza Preparedness - Final report to Governor. 2007 [cited 2013 April]; Available from: http://pandemicflu.utah.gov/docs/PandInfluTaskforceFinalReport.pdf.

21. Waugh, W.L. and G. Streib, Collaboration and Leadership for Effective Emergency Management. Public Administration Review, 2006. 66(s1): p. 131-140.

22. Hughes, R.G., Chapter 33: Professional Communication and Team Collaboration, in Patient Safety and Quality: An Evidence-Based Handbook for Nurses, Agency for Healthcare Research and Quality, Editor. 2008, Agency for Healthcare Research and Quality,: Rockville, MD.

23. Institute of Medicine, To err is human: building a safer health system. 2000, Washington, D.C.: National Academy Press.

24. Sansoni, J., et al. An Assessment Framework for Aged Care. 2012 April [cited 2013 April]; Available from: Centre for Health Service Development, University of Woolongong.

25. BRAID. Bridging Research in Ageing and ICT Development - Consolidated Vision of ICT and Ageing. 2011 [cited 2013 April]; Available from: http://auseaccess.cis.utas.edu.au/sites/default/files/D4.2\%20Final.pdf.

26. Holzman, T.G., Computer-human interface solutions for emergency medical care. Interactions, 1999. 6(3): p. 13-24.

27. Waugh, W.L., Coordination or Control: Organizational Design and the Emergency Management Function. International Journal of Disaster Prevention and Management, 1993. 2(4): p. 17-31.

28. World Health Organisation. Pandemic Influenza preparedness Framework. 2011 [cited 2013 May]; Available from: http://whqlibdoc.who.int/publications/2011/9789241503082_eng.pdf.

29. U.S. Dept of Health and Human Services. HHS Pandemic Influenza Plan. 2005 [cited 2013 May]; Available from: http://www.flu.gov/planning-preparedness/federal/ hhspandemicinfluenzaplan.pdf.

30. Thompson, A.K., et al., Pandemic influenza preparedness: an ethical framework to guide decision-making. BMC Medical Ethics, 2006. 7(12).

31. NZ National Ethics Advisory Committee. Ethical Values for Planning for and Responding to a Pandemic in New Zealand. 2006 [cited 2013 May]; Available from: http://neac.health.govt.nz/sites/neac.health.govt.nz/files/documents/publications/pandemicplanning-and-response.pdf.

32. Kristensen, M., M. Kyng, and L. Palen. Participatory Design in Emergency Medical Service: Designing for Future Practice. in Conference on Human Factors in Computing Systems - CHI 2006. 2006. Montréal, Québec / Canada.

33. Moghadas, S.M., et al., Managing public health crises: the role of models in pandemic preparedness. Influenza Other Respi Viruses, 2008. 3(2): p. 75-79.

34. DoD Architecture Framework Working Group. DoD Architecture Framework Ver 1.0. 2004 [cited 2007 Feb 2007]; Available from: http://www.dod.mil/cio-nii/docs/DoDAF_v1_Volume_I.pdf, http://www.dod.mil/cio-nii/docs/DoDAF_v1_Volume_II.pdf. 
35. ISO/IEC, Annex A: GERAM, in ISO/IS 15704:2000/Amd1:2005: Industrial automation systems Requirements for enterprise-reference architectures and methodologies. 2005.

36. EIF, European interoperability framework for pan-European eGovernment services. Luxembourg: Interoperable Delivery of European eGovernment Services to public Administrations, Businesses and Citizens (IDABC). 2004.

37. IDEAS. IDEAS Project Deliverables (WP1-WP7), Public reports. 2003 [cited 2011 Jul]; Available from: www.ideas-roadmap.net.

38. ATHENA State of the art of Enterprise Modelling Techniques and Technologies to Support Enterprise Interoperability. Deliv D.A1.1.1 2004 [cited 2011 Mar 30]; Available from: http://www.athena-ip.org.

39. Chen, D. Framework for Entrerprise Interoperability. 2006 [cited 2011 July]; Available from: http://www.fines-cluster.eu/fines/jm/Download-document/53-Framework-for-EnterpriseInteroperability-Chen.html.

40. Whitman, L. and H. Panetto, The Missing Link: Culture and Language Barriers to Interoperability. Annual Reviews in Control, 2006. 30(2): p. 233-241.

41. Australian Psychological Society. Disaster Response Network (DRN). 2013 [cited 2013 April]; Available from: http://www.psychology.org.au/medicare/drn/.

42. Bard, Y., et al., Multi-level Social Networking to Enable and Foster Collaborative Organisations, in Adaptation and Value Creating Collaborative Networks, L. Camarinha-Matos, A. PereiraKlein, and H. Afsarmanesh, Editors. 2011, Springer: Berlin. p. 477-485.

43. Cooper, S., et al., Collaborative practices in unscheduled emergency care: role and impact of the emergency care practitioner - qualitative, quantitative and summative fndings. Emergency Medicine Journal, 2007(24): p. 625-633.

44. Neumann, D., L.A. de Santa-Eulalia, and E. Zahn. Towards a Theory of Collaborative Systems. in Adaptation and Value Creating Collaborative Networks (Proceedings of the $12^{\text {th }}$ IFIP Working Conference on Virtual Enterprises - PROVE 11). 2011. São Paulo / Brazil: 362.

45. Tierney, K. and E.L. Quarantelli, Needed Innovation in the Delivery of Emergency Medical Services in Disasters: Present and Future. Disaster Management, 1989. 2(2): p. 70-76.

46. Noran, O., Collaborative networks in the tertiary education industry sector: a case study. International Journal of Computer Integrated Manufacturing, 2013. 1-2: p. 29-40.

47. Queensland Health. Allied health career structure. 2012 [cited 2013 April]; Available from: http://www.health.qld.gov.au/allied/career-structure.asp.

48. Pava, C., Managing New Office Technology, An Organisational Strategy. 1983, Y: Free Press.

49. McGregor, D., The Human Side of Enterprise. 1960, New York: McGraw-Hill.

50. Keen, P.G.W. and M. Scott Morton, Decision Support Systems: An Organisational Perspective. 1978, Reading, Massachussetts: Addison-Wesley.

51. Iivari, J., A Paradigmatic Analysis of Contemporary Schools of IS Development. Eur. J. Information Systems, 1991. 1(4): p. 249-272.

52. Australian Government. Attorney's General's Office - Emergency Management in Australia. 2011 [cited 2011 Mar 30]; Available from: http://www.ema.gov.au/.

53. Council of Australian Governments. National E-health Strategy. 2008 [cited 2013 April]; Available from: http://www.ahmac.gov.au/cms_documents/national\%20e-health\%20strategy.pdf.

54. Alpay, L., et al., Current Challenge in Consumer Health Informatics: Bridging the Gap between Access to Information and Information Understanding. Biomed Inform Insights, 2009.2(1):p.1-10. 